\title{
SIGNIFICADO DO TRABALHO UM ESTUDO ENTRE TRABALHADORES INSERIDOS EM ORGANIZAÇÕES FORMAIS
}

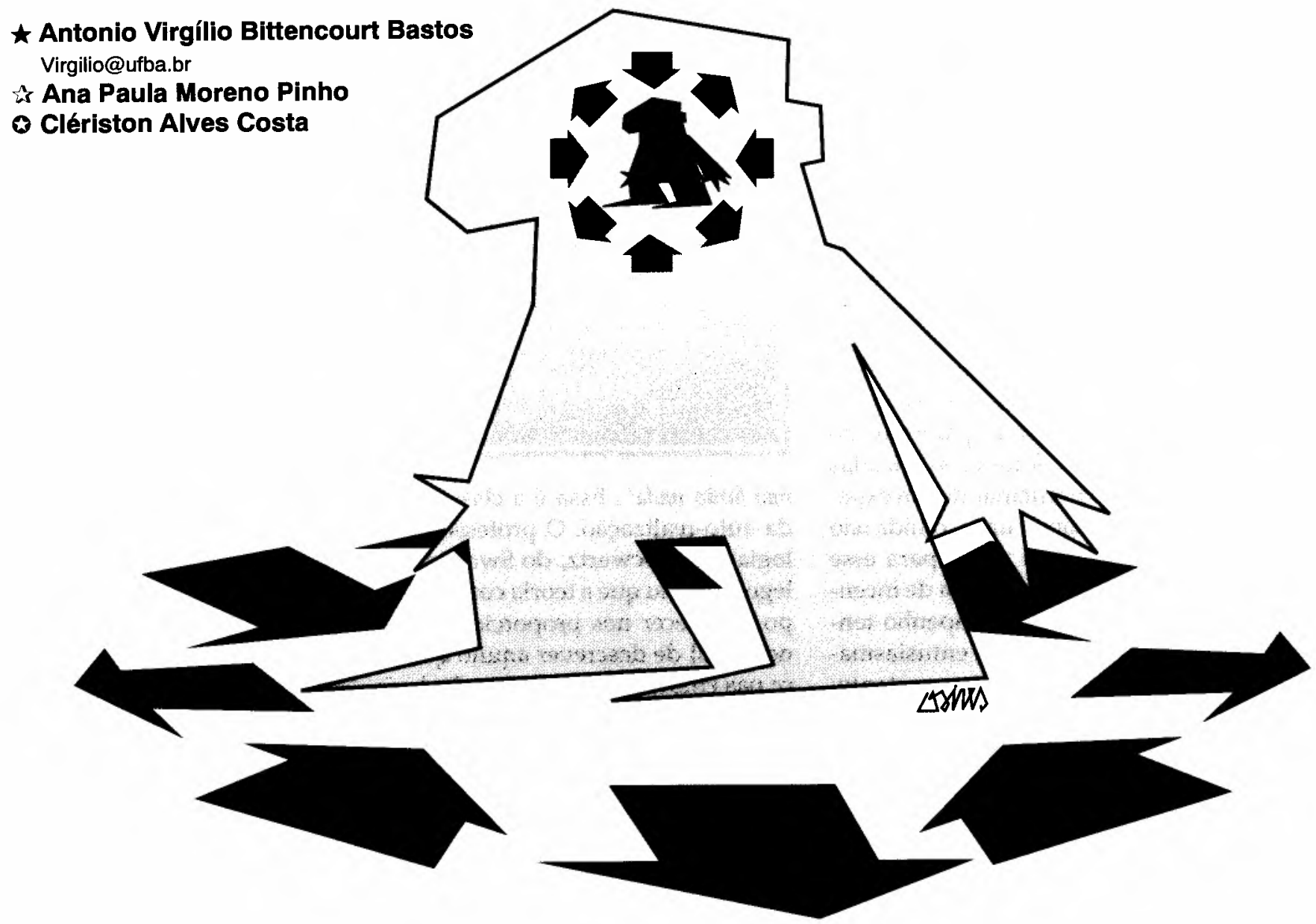

PALAVRAS-CHAVE:

significado do trabalho, centralidade do trabalho, valores relativos ao trabalho, normas societais relativas ao trabalho.

\section{KEY WORDS:}

meaning of working, work centrality, work values, societal norms and work.

^ Professor do Departamento de Psicologia da UFBA e Pesquisador do Centro de Estudos Interdisciplinares para o Setor Público (ISP/UFBA).

* Bolsista de Iniciação Científica do Programa UFBA/CNPq.

Bolsista de Iniciação Científica do Programa UFBA/CNPq.

(rae@eaesp.fgvsp.br) Assinatura E-mail 


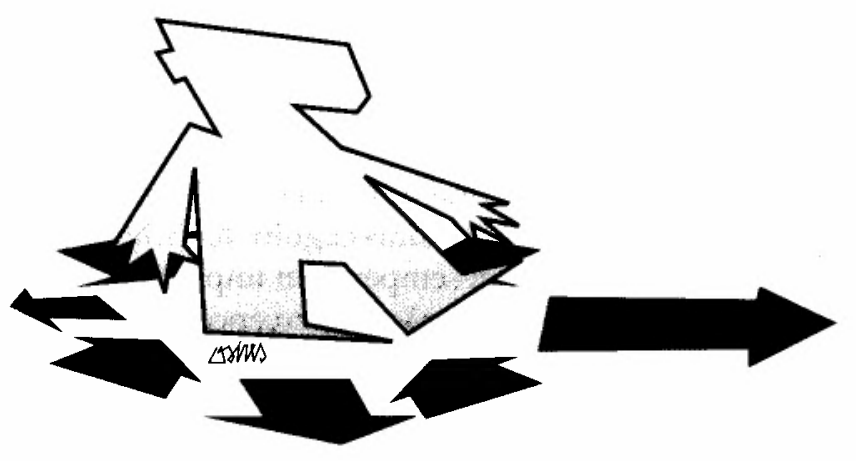

Semelhanças e diferenças entre o estudo do Meaning of Working International Research Team (1987) para oito países e de Soares (1993) para o Brasil, com base numa aplicação dos dados relativos ao contexto brasileiro.

Resemblances and differences between the Meaning of Working International Research Team's study for eight countries (1987) and Soares' (1993) for Brazil, based on an application of the relative data to the Brazilian context.

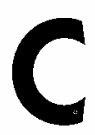
omo constata Lévy-Leboyer, "as atitudes coletivas frente ao trabalho foram submetidas a profundas reviravoltas e o significado do trabalho, assim como a sua importância frente a outras atividades humanas, muda ao longo dos séculos de maneira radical e numerosas vezes sucessivamente" 1 . Hoje, prossegue a autora, as mudanças sociais, econômicas, tecnológicas e seus impactos na estrutura de emprego e condições de trabalho estão implicando uma complexa e multifacetada "crise das motivações": um "enfraquecimento do valor social e psicológico da atividade profissional (...) desaparecimento progressivo da ética do trabalho e da consciência profissional" 2 . Parece haver, como assinalam Harman e Horman, uma incapacidade da sociedade moderna, independentemente de modelos político-econômicos existentes, de se organizar de forma a garantir a todos os cidadãos "amplas oportunidades de encontrar um trabalho significativo e satisfatório"3.

A relevância que a esfera de vida pessoal ocupada pelo trabalho adquire para a maioria das pessoas das sociedades modernas é evidente quando se observa que ele é utilizado como definidor da estrutura de tempo (dias, meses, anos), divisor entre atividades pessoais (autodeterminadas) $\mathrm{e}$ impessoais (heterodeterminadas), legitimador social de diferentes fases da vida (estudo, trabalho e aposentadoria), como afirmam Quitanilla e Wilpert ${ }^{4}$. Além disso, o trabalho se coloca como uma necessi- dade existencial, cujos rendimentos servem para a satisfação de necessidades humanas (alimentação, moradia, educação, lazer, bem-estar social, arte e prestígio), tornando-se, portanto, um elemento crítico contribuidor para o autoconceito e identidade pessoais. Assim, o trabalho possui um forte caráter estruturante nos níveis pessoal e social ${ }^{5}$.

O momento de intensas transformações sociais, econômicas, tecnológicas e políticas que marcam este final de século é fértil em estimular, em perspectivas diferenciadas, análises sobre os determinantes e possíveis alterações no significado do trabaIho para os indivíduos. Nesse contexto, inserem-se alterações importantes nas atitudes e valores relativos ao trabalho, como destacam Northcraft e Neale ${ }^{6}$ e Offerman e Gowing 7 . Cresce o desejo de autonomia, de participação, de experiências de trabalho significativas, de maior envolvimento nas decisóes que afetam o indivíduo, de equilíbrio entre o trabalho e outras esferas da vida.

\section{ACERCA DO TRABALHO E DE SEU SIGNIFICADO}

Um rápido exame do uso do termo trabalho na nossa linguagem cotidiana deixa explícitos dois grandes eixos de significados com componentes avaliativos claramente antagônicos. Tais eixos refletem, certamente, as grandes tradições (histórico-
1. LEVY-LEBOYER, C. A crise das motivações. São Paulo: Atlas, 1994, p. 50.

2. Idem, ibidem, p. 59.

3. HARMAN, W., HORMAN, J. O trabalho criativo - o papel construtivo dos negócios numa sociedade em transfor mação. São Paulo: Cultrix, 1992, p. 26.

4. QUITANILLA, S. A. R. WILPERT, $B$. The meaning of working - scientific status of a concept. In: KEYSER, V., QVALE, T., WILPERT, B., QUITANILLA, S. A. R. (eds.). The meaning of work and technological options. Chischester, New York: John Wiley \& Sons, 1988.

5. TEZANOS, J. F. Transformações na estrutura de classes na sociedade tecnológica avançada. O socialismo no futuro. Ofuturo do trabalho. Salvador: Instituto Pensar, n. 6, p. 67-87, 1993; CAMPS, V. O sentido do trabalho e o ethos in dividualista. O futuro do trabalho. Salvador: Instituto Pensar, n. 6, p. 123-32, 1993.

6. NORTHCRAFT, G. B., NEALE, M. A. Organizational behavior: a management challenge. Chicago: The Dryden Press, 1990.

7. OFFERMAN, L. R., GOWING $M$. K. Organizations of the future: changes and challenges. American Psychologist, v. 45, n. 2, p. 95-108, 1990. 
filisófico-religiosas) que modelaram a dimensão avaliativa/afetiva com que nos reportamos ao "trabalho" na atualidade8

O primeiro eixo, talvez dominante, vincula o trabalho à noção de sacrifício, de esforço incomum, de carga, fardo, algo esgotante para quem o realiza. Trabalho como sinônimo de luda, lida, lide. "Dar trabalho" significa algo que implica esforço, atenção, que causa transtorno ou preo-

cupação. Nesse eixo, trabalho associa-

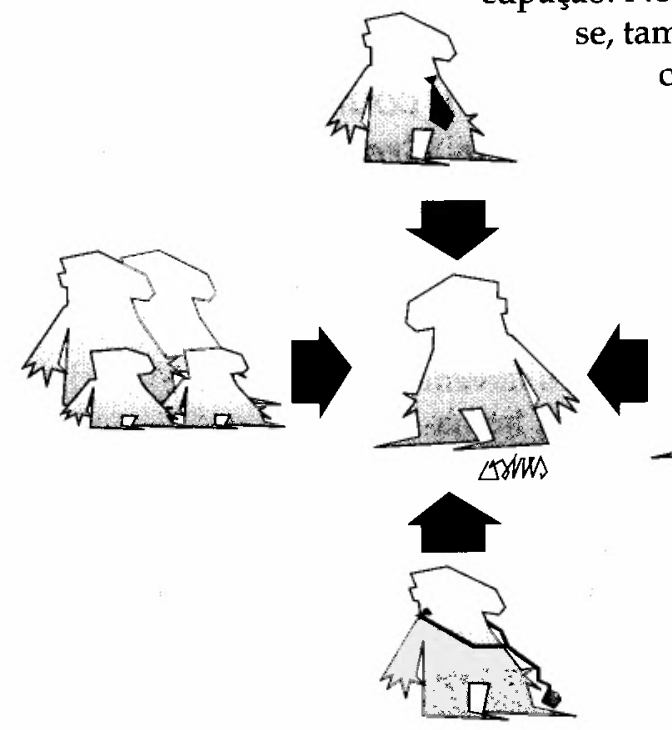

como está no Antigo Testamento (punição pelo pecado original), de onde decorre o sentido de obrigação, dever, responsabilidade. Essa vertente que, poderíamos dizer, traz uma avaliação negativa do trabalho - relaciona-se diretamente ao significado do termo latino que originou o palavra trabalho (tripalium, instrumento de tortura; trabalhar tem origem em tripaliare, ou martirizar com o tripalium).

Há um segundo eixo avaliativo, com uma clara valorização positiva, que vê o trabalho como a aplicação das capacidades humanas para propiciar o domínio da natureza, sendo responsável pela própria condição humana. Acompanha a noção de empenho, esforço para atingir determinado objetivo. Trabalhar algo, significa também fazer com cuidado, esmerar-se na execução de uma ação, de uma tarefa. Na tradição cristã, com a Reforma protestante, o trabalho passa a ser visto como instrumento da salvação e forma de realizar a vontade divina. Na tradição oriental, as religiões tendem a ver o trabalho como uma atividade que harmoniza os homens com a natureza e que desenvolve o seu caráter 9 .

Em uma perspectiva psicológica e cognitivista, admite-se que a experiência cotidiana dos indivíduos constitui a base sobre a qual eles constroem suas percepçōes e conhecimentos acerca do mundo que os cerca. Tal construção, embora de base individual, é um processo eminentemente social, por se dar no interior de um conjunto partilhado de crenças, valores e significados que definem o contexto cultural no qual as interações entre indivíduos e grupos ocorrem. No nível individual, esses conhecimentos e percepções se organizam em estruturas cognitivas (schemas, frames) que desempenham importante papel na determinação de percepções e comportamentos futuros em relação aos objetos, situaçōes ou pessoas, ao permitirem ao indivíduo identificar padrões globais, sobre os quais reagem.

Nesse sentido, o significado subjetivo do trabalho pode ser conceitualizado como uma estrutura cognitiva, um schema, que tem forte impacto sobre as percepções, avaliações, atribuições, e sobre o próprio comportamento do indivíduo no trabalho. Apesar de não existir uma teoria claramente formulada que organize o corpo de conhecimentos existente e da qual possam ser retiradas implicações políticas pertinentes, há uma tentativa importante de sistematizar o conceito de "significado do trabalho" em um estudo desenvolvido por uma equipe de pesquisadores (Meaning of Working International Research Team $)^{10}$. Esse grupo conduziu, nos anos 80 , uma ampla pesquisa comparativa acerca do "significado do trabalho" em oito países, que passaremos a comentar a seguir, por constituir a base do presente estudo.

Uma das principais contribuições do estudo consistiu, de início, na construção do próprio conceito de "significado do trabalho", articulando outros conceitos que contam com tradiçōes de pesquisa bem mais estabelecidas. Há, assim, uma tentativa de recompor uma área de estudo excessivamente fragmentada, buscando apreender como o indivíduo articula suas percepções relativas a diversas dimensões do trabalho.

A estrutura geral do conceito de significado do trabalho envolve três grandes domínios: a centralidade do trabalho, as normas societais do trabalho, e os resultados e objetivos valorizados do trabalho. Sobre esses três grandes campos definidores do construto nos deteremos a seguir. 
Centralidade do trabalho

A centralidade do trabalho é definida como o grau de importância geral que o trabalho possui na vida de um indivíduo em determinado momento ${ }^{11}$, independentemente das razões às quais se atribui tal importância (por exemplo, ocupar parte significativa do seu tempo, propiciar ganhos econômicos ou psicológicos, ou implicar custos decorrentes da sua inter-relação com outras esferas vitais, como família, lazer, religião ou vida comunitária).

Para o MOW'2, a centralidade do trabatho define-se como "uma crença geral acerca do valor do trabalho na vida do indivíduo", constituindo-se de dois componentes teóricos: a. valorativo, o trabalho como o papel desempenhado na vida; e b. orientação para a decisão sobre as esferas de vida preferidas. Enquanto o primeiro toma o próprio self como referência para avaliar a importância do trabalho, o segundo toma as demais esferas ou papéis desempenhados pelo indivíduo.

O componente valorativo apresenta duas propriedades:

- identificação: resultante de processos cognitivos que envolvem a comparação do trabalho como atividade com a percepção do self, podendo o trabalho ser central ou periférico na definição da sua auto-imagem;

- envolvimento ou comprometimento: implica respostas comportamentais e afetivas ao trabalho, indicando o grau em que o trabalho é considerado, pelo indivíduo, como parte de sua própria vida. Esses dois componentes são vistos como mutuamente reforçadores.

Resultados ou produtos valorizados do trabalho

Os resultados ou produtos valorizados do trabalho relacionam-se com as finalidades que as atividades de trabalho possuem para o indivíduo, respondendo à indagação acerca do porquê o indivíduo trabalha. Seria o componente motivacional, segundo a definição de Quitanilla e Wilpert ${ }^{13}$. As informaçóes sobre produtos valorizados permitem entender o que torna os indivíduos mais ou menos satisfeitos com suas ocupações ou o que torna uma situação de trabalho mais atrativa do que outra. Tratase, portanto, de um conceito associado às noçōes de satisfação e motivação, como assinala Soares ${ }^{14}$, sendo, por conseguinte, o mais estudado dentre os domínios do significado do trabalho.

No estudo desenvolvido pelo MOW, os produtos valorizados do trabalho envolvem as seguintes funçōes abrangentes, expressivas e instrumentais, que o trabalho



pode desempenhar para o indivíduo, apoiando-se largamente na proposta de Kaplan e Tausky ${ }^{15}$ : a. o trabalho que permite a obtenção de status e prestígio; b. a funçāo econômica, obtençāo dos rendimentos necessários; c. a função de manter o indivíduo ocupado, em atividade; d. a funçāo de contato social, de permitir estabelecer relaçōes interpessoais; e. a funçāo de se sentir fazendo algo átil à sociedade; e f. a função auto-expressiva ou intrínseca, quando se valoriza o trabalho interessante e que permite a auto-realização.

\section{Normas societais relativas ao trabalho}

Um terceiro componente importante do significado do trabalho consiste na relação que o indivíduo estabelece com as normas socialmente aceitas acerca do trabalho. Nos sistemas sociais, tais normas são ingredientes importantes para viabilizar e manter a coesāo dos grupos. Tais normas funcionam como padrōes sociais que balizam as avaliações individuais acerca das recompensas obtidas pelo trabalho ${ }^{16}$.

Quanto a este domínio do significado do trabalho, o estudo realizado pelo MOW ${ }^{17}$ utilizou-se de princípios do raciocínio nor-
11. ENGLAND, G. W. MISUMI J. Work centrality in Japan and United States. Journal of Cross-Cultural Psychology, v. 17 , n. 4, p. 399-416, 1986.

12. MOW. Op. cit., p.17

13. QUITANILLA, S. A. R., WILPERT, B. Op. cit.

14. SOARES, C. R. Significado do trabalho: um estudo comparativo de categorias ocupacionais. Brasilia: Instituto de Psicologia Universidade de Brasilia, 1992. (Dissertaçāo de Mestrado)

15. KAPLAN, H. R., TAUSKY, C. The meaning of work among the hard core unemployed. Pacific Sociological Review, v. 17, p. 185-98, 1974

16. QUITANILLA, S. A. R. WILPERT, B. Op. cit.

17. MOW. Op. cit. 


\begin{tabular}{|c|c|c|}
\hline $\begin{array}{c}\text { TABELA } \\
1\end{array}$ & \multicolumn{2}{|c|}{$\begin{array}{l}\text { Distribuiçäo dos trabalhadores da amostra por } \\
\text { caracteristicas pesssoais e funcionais }\end{array}$} \\
\hline Variáveis pessoals & & Variávels funcionals \\
\hline Sexo & $(\%)$ & Ocupação \\
\hline Homens & 55,4 & Técnicas e científicas \\
\hline Mulheres & 44,6 & $\begin{array}{ll}\text { Administrativas } & 33,5 \\
\text { Industriais e de producão } & 14,7\end{array}$ \\
\hline \multirow{3}{*}{$\begin{array}{l}\text { Escolaridade } \\
\text { Segundo grau } \\
\text { Superior }\end{array}$} & \multirow{3}{*}{$\begin{array}{l}(\%) \\
57,5 \\
42,5\end{array}$} & \\
\hline & & Sindicalização (\% de SIM) 64,1 \\
\hline & & Chefia ( $\%$ de sim) \\
\hline $\begin{array}{l}\text { Idade } \\
\text { (média em anos) }\end{array}$ & 35,1 & $\begin{array}{l}\text { Tompo de serviço } \\
\text { (média em anos) }\end{array}$ \\
\hline
\end{tabular}

mativo e justiça social, observando dois conjuntos antagônicos:

- deveres: padrões sociais considerados corretos dos indivíduos para com a sociedade, na situação de trabalho; incluemse aqui noções como a de que todo indivíduo tem o dever de contribuir para a sociedade através do trabalho; deveria pensar na melhor forma de fazer o seu trabalho; e deveria aceitar qualquer trabalho desde que a remuneração compensasse;

- direitos: normas subjacentes ou obrigações da sociedade para com o indivíduo; incluem-se, nesta categoria, as noções de que todo indivíduo tem direito a um trabalho interessante e significante; que $o$ empregador deve treinar o trabalhador quando desatualizado; e que o trabalhador deve participar das decisóes relativas ao trabalho.

As normas sociais consistem numa expressão geral do que seriam trocas equitativas entre o que o indivíduo recebe da situação de trabalho e as contribuições que ele traz para o processo de trabalho.

No Brasil, Soares ${ }^{18}$ investigou o significado do trabalho a partir do referencial teórico e instrumental proposto pelo MOW, em uma amostra de 915 sujeitos, trabalhadores de sete organizações públicas (admi- nistração direta e indireta) e privadas de Brasília. Diferentemente do estudo original, este envolveu apenas o trabalho remunerado, realizado em instituições formais.

Considerando-se que são reduzidas as pesquisas que investigam aspectos psicossociais do trabalhador brasileiro, o presente estudo teve como objetivo principal descrever o trabalho, em uma amostra de trabalhadores baianos. Buscou-se, ainda, em uma perspectiva descritiva, comparar os resultados obtidos nesse contexto com dados dos estudos realizados por Soares ${ }^{19} \mathrm{e}$ pelo $\mathrm{MOW}^{20}$, alargando a compreensão da singularidade com que o fenômeno, foco da investigação, apresenta-se no contexto estudado.

\section{O DESENVOLVIMENTO DO ESTUDO}

Os dados foram coletados em vinte organizações (quatro empresas públicas prestadoras de serviços de infra-estrutura e financeiras, sete órgãos de administração pública direta e nove empresas privadas), totalizando 1.013 participantes, na região metropolitana de Salvador, Bahia. As características da amostra encontram-se na tabela 1.

Para a coleta de dados, utilizou-se uma versão reduzida dos itens que integram o questionário proposto pelo MOW, traduzido e validado para o contexto brasileiro por Soares ${ }^{21}$. Os questionários foram respondidos, sob a assistência de um auxiliar de pesquisa, no local de trabalho. Os dados foram codificados e preparados para análise estatística, tendo-se utilizado o SPSS para calcular as freqüências e as medidas de tendência central (médias, medianas e modas), e medidas de dispersão. Foram efetuados cruzamentos dos escores de centralidade por diversas variáveis que caracterizam a amostra, utilizando-se procedimentos de análise de variância.

\section{OS PRINCIPAIS RESULTADOS}

Os resultados, apresentados a seguir, possuem caráter basicamente descritivo. A carência de dados relativos ao significado do trabalho para brasileiros, e em que medida eles se aproximam ou se afastam de trabalhadores de outros países, tornam re- 
levante o caráter descritivo da apresentação dos dados. Eles se encontram estruturados segundo as três grandes dimensões que definem o construto de significado do trabalho.

\section{A centralidade do trabalho}

Em um primeiro momento, podemos observar, na tabela 2, o peso atribuído ao trabalho comparativamente às demais esferas da vida investigadas, confrontandose os dados obtidos no presente estudo com os resultados de estudos realizados.

Os resultados obtidos, como facilmente se observa, são bastante próximos daqueles encontrados no único estudo realizado no Brasil. As pequenas diferenças nos escores médios (maior valorização da comunidade e do trabalho em detrimento da família, lazer e religião, entre os baianos) não chegam a alterar a ordem com que brasilienses e baianos avaliaram as diferentes esferas de vida pessoal.

Quando os resultados da Bahia são comparados aos dados de outros países levantados pelo MOW, indicam que o padrão encontrado na Bahia aproxima-se daquele observado nas sociedades ocidentais, diferenciando-se do Japão, onde o peso do trabalho é mais elevado, superando inclusive a esfera família. Os pesos atribuídos pelos trabalhadores baianos a trabalho $e$ família mostram-se bem próximos daqueles encontrados entre os trabalhadores da Bélgica, Holanda e Alemanha. Nesses três países, contudo, verifica-se uma maior valorização do lazer e menor valorização da religião e comunidade. Nas amostras dos Estados Unidos e da Inglaterra, o menor peso atribuído à esfera trabalho associa-se a uma maior valorização da religião e do lazer, no primeiro, e do lazer e da família, no segundo. $O$ peso relativamente menor do lazer quando comparado aos resultados de outros países, especialmente os europeus, e sobretudo a Inglaterra, no entanto, contraria a expectativa difundida acerca do comportamento do baiano em relação ao trabalho. Por outro lado, o peso atribuído à religião (inferior apenas àquele observado entre brasilienses e norte-americanos) revela-se congruente com a presença da religiosidade como um forte traço cultural baiano.

\begin{tabular}{|c|c|c|c|c|c|c|c|c|c|}
\hline \multirow{2}{*}{$\begin{array}{c}\text { TABELA } \\
2 \\
\\
\text { Esforas da vida } \\
\end{array}$} & \multicolumn{9}{|c|}{$\begin{array}{l}\text { Escores médios de importância do trabalho e } \\
\text { demais esferas da vida, comparativamente aos } \\
\text { dados de outros estudos }\end{array}$} \\
\hline & Bahia & Brasilita' & Japắo? & |sraet| & USA2 & Alomanha ${ }^{2}$ & inglaterra ${ }^{2}$ & Holanda" & Bélgica ${ }^{2}$ \\
\hline Lazer & 15.9 & 16.2 & 19.7 & 18.2 & 18.1 & 22.7 & 22.3 & 24.2 & 24.6 \\
\hline Comunidade & 9.8 & 7.7 & 5.3 & 4.5 & 9.9 & 7.3 & 7.8 & 7.5 & 6.0 \\
\hline Trabalho & 29.5 & 27.7 & 36.1 & 28.3 . & 24.5 & 28.0 & 21.5 & 29.6 & 29.9 \\
\hline Aoligláo & 10.2 & 11.9 & 3.7 & 4.9 & 14.0 & 5.2 & 8.6 & 4.9 & 4.9 \\
\hline Familia & 34.1 & 36.8 & 35.1 & 43.8 & 33.6 & 36.7 & 40.1 & 33.7 & 34.7 \\
\hline
\end{tabular}

Com exceção do Japão e da Inglaterra, constata-se que, apesar das diferenças entre os escores médios apresentados, há uma mesma seqüência na avaliação feita pelos trabalhadores quanto à importância relativa das cinco esferas vitais investigadas. A família, o trabalho e o lazer, neste estudo, como nas pesquisas internacionais, são as três esferas de maior importância na vida dos indivíduos e aquelas que, provavelmente, competem pela dedicação e compromisso do trabalhador e podem se transformar em fonte de conflitos individuais com a família ou com a organização empregadora.

Além de se trabalhar com a centralidade a partir de uma avaliação comparativa do trabalho frente a outras esferas da vida, calculou-se um escore global de centralidade do trabalho. Esse escore envolveu um cálculo estatístico que agregou o peso atribuído às diferentes esferas da vida e o item isolado em que o respondente dizia quando o trabalho era central na sua vida. Esse escore podia variar de 2 (baixa centralidade, quando o trabalho não é central e foi a esfera que obteve menos pontos entre as cinco apresentadas) a 10 pontos (alta centralidade, na situação oposta).

Com escores que podiam variar de 2 (baixa centralidade) a 10 pontos (alta centralidade), observamos que os trabalhadores baianos apresentaram um escore médio de 6,39 (ligeiramente acima do ponto intermediário). A distribuição dos casos 


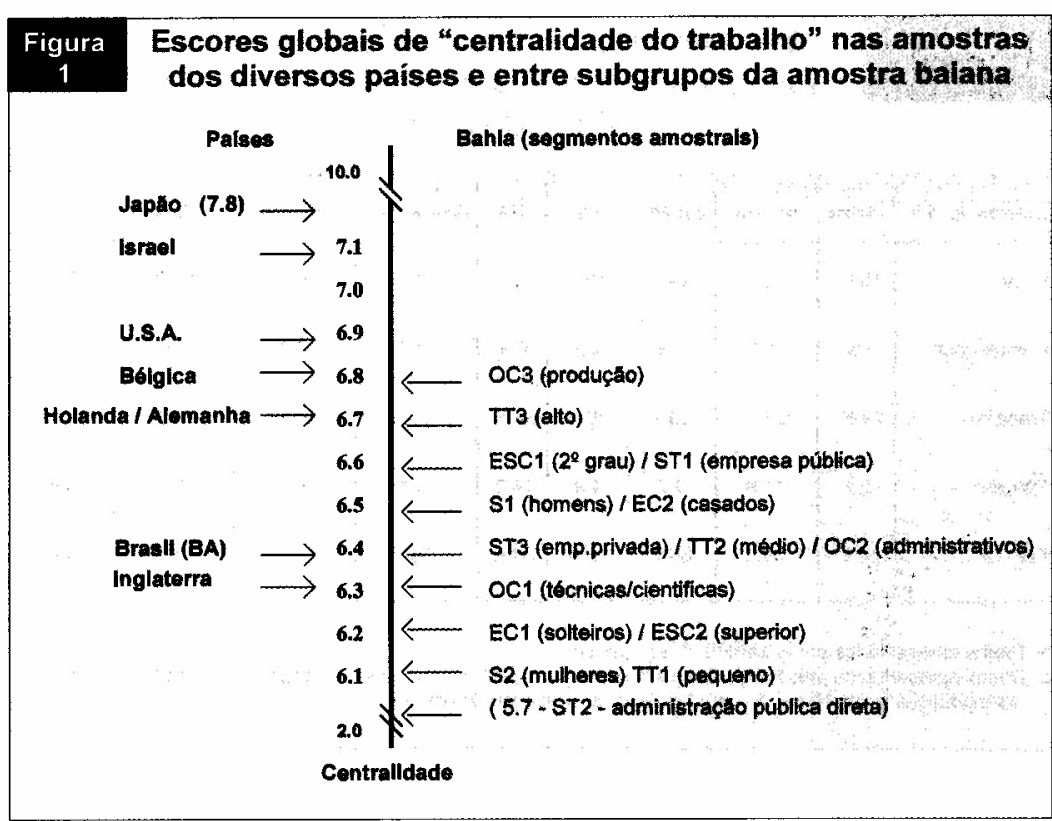

por escones revela uma concentração maior entre o escore 7 (o valor mais freqüente, $23,2 \%)$ e os escores $6(19,8 \%)$ e $5(19,2 \%)$.

Na figura 1, os resultados da amostra global são comparados com os obtidos em outros países, ao mesmo tempo em que são comparados os escores de subgrupos específicos da amostra baiana.

O escore médio observado compara-se com aquele encontrado na amostra da Inglaterra, no estudo realizado pelo MOW. Tal escore, quando comparado com o dos demais países da pesquisa original, revela que nos encontramos entre aqueles com menor nível de centralidade do trabalho na vida, e está bem distante dos escores encontrados nas amostras de trabalhadores japoneses, israelenses ou norte-americanos.

Há, todavia, diferenças importantes no grau de centralidade entre alguns segmentos da amostra, como se vê ainda na figura 1. Destacam-se com escores mais elevados: os trabalhadores de ocupações industriais (OC3), os que se encontram na etapa mais avançada da carreira (TT3), os que possuem escolaridade de segundo grau (ESC2) ou trabalham em empresas públicas (SET1). Destacam-se com os escores mais baixos de centralidade: o pessoal que trabalha na administração pública (SET2) e os

22. LÉVY-LEBOYER, C. Op. cit.

23. Dados apresentados por SOARES, C. R. Op. cit. do comparados às mulheres, é um resultado similar ao obtido na amostra global do MOW.

Assim, fatores pessoais como escolaridade, a natureza da ocupaçăo e setor de trabalho se mostram diferenciadores significativos na avaliação da centralidade do trabalho na vida dos indivíduos. A evidência de menor centralidade entre os servidores públicos, em contrapartida ao maior escore daqueles que atuam em empresas públicas, é reveladora do impacto das políticas de recursos humanos (ou ausência de...) desenvolvidas nesses dois contextos. O tempo de trabalho pode refletir mudanças nos valores sociais relativos ao trabalho, como já assinalado anteriormente. Por outro lado, menor escolaridade, assim como o desempenho de ocupações industriais, talvez até pela adversidade dessas condições, parecem conduzir o trabalhador a verbalizar avaliações mais positivas relativas à importância do trabalho na sua vida, algo que pode cumprir a função de reduzir a dissonância ou tornar congruentes, para cada indivíduo, as suas cogniçóes e o seu comportamento.

Tais diferenças entre subgrupos amostrais fortalecem a idéia de que a relação indivíduo-trabalho é complexa e dependente de múltiplos fatores, como assinala Lévy-Leboyer ${ }^{22}$.

\section{Os produtos valorizados do trabalho}

Múltiplos aspectos relacionados à atividade laboral podem representar facetas que a tornam mais atraente para o indivíduo, atuando como fatores motivacionais ou fontes de satisfação pesssoal. Na tabela 3 podem-se observar os escores médios de importância atribuída aos produtos do trabalho, comparativamente aos dados de Brasília $^{23}$.

No geral, os escores médios dos diversos produtos não apresentaram grande variação, constatando-se um peso levemente acentuado de dois deles frente aos demais, tanto na amostra baiana como na brasiliense. Realização pessoal e rendimentos necessários são os dois produtos que obtiveram escores médios um pouco mais elevados, havendo um certo equilíbrio entre a importância atribuída a esses aspectos polarizadores, revelando a expectativa 
de que o trabalho tem uma função instrumental não apenas no sentido de garantir os ganhos necessários, mas, também, como fonte de crescimento e auto-realização. No que se refere a status e a prestígio, os resultados apontados pelas diferentes pesquisas são congruentes, à medida que os colocam como o produto menos valorizado.

No estudo realizado pelo MOW não se observa o equilíbrio entre os aspectos expressivos e econômicos aqui encontrados. O objetivo de garantir os rendimentos necessários apareceu como o aspecto mais valorizado em todos os países, especialmente o Japão e a Alemanha. Entre os holandeses é que se encontrou um padrão que mais se aproxima do visto no presente estudo; a valorização de aspectos intrínsecos ou expressivos do trabalho é praticamente igual à dos aspectos econômicos, sendo o país em que maior peso foi atribuído ao objetivo de servir à sociedade. De forma similar à Bahia e Brasília, a busca de status e prestígio é o aspecto com menor valorização, em praticamente todos os países, especialmente na Holanda.

Tendo-se realizado uma análise fatorial dos sete itens, encontraram-se dois principais fatores ortogonais em que se estrutura a postura dos trabalhadores baianos frente aos produtos valorizados do trabalho. O primeiro fator (PROVAL 1) opõe os que valorizam o trabalho que permite a realização pessoal (escores mais baixos) àqueles que valorizam o trabalho como fonte de contato interpessoal e possibilitador de se manter em atividade (altos escores). O segundo fator (PROVAL 2) contrapõe os que valorizam o rendimento (altos escores) aos que valorizam a tarefa em si considerada interessante (baixos escores).

No geral, observou-se que a amostra estudada, no primeiro fator, tende ligeiramente a valorizar o contato interpessoal $\mathrm{e}$ a atividade (escore médio de 10,49). Frente ao segundo, há uma tendência do grupo a valorizar mais fortemente o rendimento do que a natureza interessante das tarefas (média de 10,82). Foram detectadas, todavia, diferenças importantes entre alguns segmentos da amostra, o que pode ser visto na figura 2.

Novamente aqui, variáveis como escolaridade, ocupação, setor da administração
TABELA Escores médios do peso atribuído aos produtos 3 do trabalho nas amostras da Bahia e de Brasília

\begin{tabular}{|l|c|c|}
\hline Produtos valorizados do trabalho & Bahia & Brasília \\
\hline O trabalho que fornece status e prestigio & 8.88 & 8.14 \\
O trabalho que fornece rendimentos & 19.46 & 21.96 \\
necessários & 12.91 & 12.84 \\
O trabalho que mantém ativo (ocupado) & 12.54 & 13.16 \\
O trabalho que permite contatos interpessoais & 13.35 & 14.29 \\
O trabalho que é um modo útil de servir & 11.70 & 11.10 \\
a sociedade & 20.56 & 19.13 \\
\hline
\end{tabular}

e posição de chefia são os mais fortes aspectos associados a diferenças na importância atribuída a cada produto ou valor do trabalho. O simples exame da figura permite perceber que níveis elevados de valorização de contatos e atividade se associam à valorização do trabalho em si interessante (pontos localizados no quadrante IV). Por outro lado, aqueles que valorizam a auto-realização também tendem a valorizar os ganhos ou remuneração auferida com o trabalho (pontos no quadrante II). Esses dois fatores destacam uma lógica mais instrumental (o trabalho como meio para obter ganhos e realização) e outra mais intrínseca, que valoriza o própria atividade e o contexto em que esta é realizada.

Dentre as diferenças significativas constantes na figura 2, vêem-se os trabalhadores de ocupações industriais (OC3) e ad-

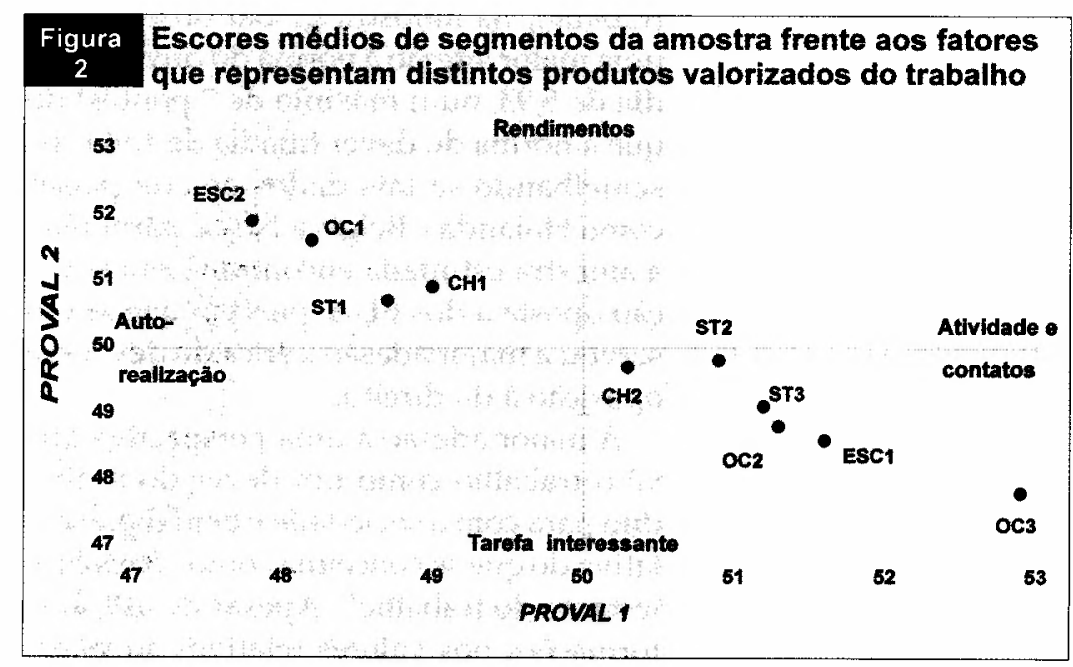




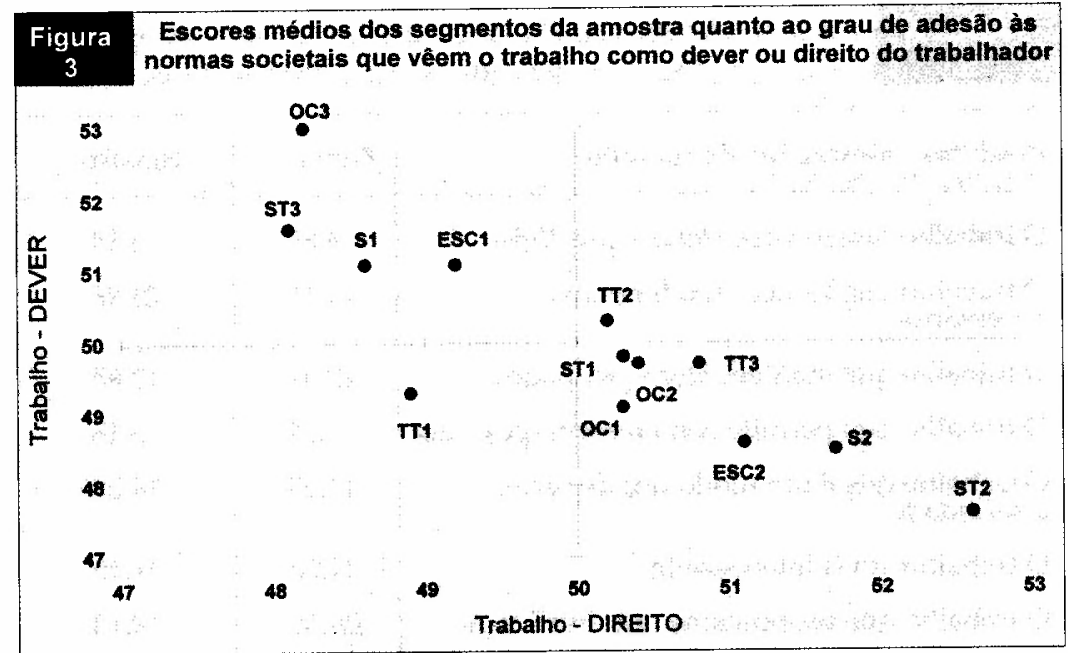

ministrativas ( $\mathrm{OC} 2)$, ou aqueles com escolaridade secundária (ESC1), como representantes dos valores mais extremos no quadrante, o que explicita uma maior valorização da atividade/contato e tarefas interessantes. Com intensidade menor encontram-se os grupos que atuam em empresas privadas (ST3) e administração pública direta (ST2), e os não-chefes ( $\mathrm{CH} 2$ ). Antagonicamente, os trabalhadores de profissões técnico-científicas (OC1), ou os que possuem escolaridade superior (ESC1), situam-se no quadrante oposto: valorizam mais a auto-realização e os rendimentos auferidos com o trabalho. Nessa situação encontram-se, ainda, aqueles que ocupavam alguma chefia $(\mathrm{CH} 1)$ e os que trabalhavam em empresas públicas (ST1).

\section{As normas societais relativas ao trabalho}

Quanto às normas societais relativas ao trabalho, na amostra global observou-se uma maior adesão à norma do direito (média de 5,93, num máximo de 7 pontos) do que à norma do dever (média de 4,96 ), assemelhando-se tais dados aos de países como Holanda e Bélgica. Nesse particular, a amostra estudada encontra-se em situação oposta à dos EUA, país em que se observou a maior adesão à ética do dever em oposição à do direito.

A maior adesão a uma perspectiva que vê o trabalho como um dever do indivíduo para com a sociedade é bem representativa do que se conceitua como "ética protestante do trabalho". Apesar de as transformaçōes nos valores relativos ao traba- lho caminharem na direção de uma revisão dos princípios que apóiam tal ética, os escores médios observados revelam, ainda, um importante nível de aceitação dos seus fundamentos, apesar de não tão forte quanto em países como os Estados Unidos, no geral tomado como o mais representativo de tal postura frente ao trabalho.

Também nessa dimensão de significado do trabalho foram observadas diferenças significativas entre segmentos da amostra, como se vê na figura 3.

Dois subgrupos da amostra situam-se em posiçōes menos "balanceadas". Os trabalhadores da administração pública (ST2) apresentam o mais elevado escore de concordância com as normas de direito e mais baixo com as normas de dever, diferenciando-se dos trabalhadores das empresas privadas (ST3). A posição oposta é encontrada entre os trabalhadores de ocupações industriais (OC3), em relação aos de ocupação técnico-científicas (OC1) e administrativas (OC2). Escolaridade e sexo são também duas variáveis que diferenciam os níveis de adesão às normas. Os homens (S1) e os que possuem escolaridade de segundo grau (ESC1) tendem a encarar o trabalho mais como dever do que como direito, ao contrário das mulheres (S2) e do pessoal do nível superior de escolaridade (ESC2). Uma posição "balanceada" encontra-se nos trabalhadores das empresas públicas (SET1), e nas ocupações administrativas (OC2). Nos subgrupos de estágios na carreira (TT2, TT3), há, também, um nível aproximado de adesão aos dois conjuntos de normas, embora os trabalhadores com menor tempo de trabalho (TT1) tendam a discordar de ambos os conjuntos de normas (mais fortemente, do trabalho como dever).

Em larga medida, as diferenças observadas quanto a gênero $e$ à escolaridade são congruentes com os dados obtidos pelo MOW. Em quase todos os países, de forma mais forte na Holanda e Bélgica, níveis mais elevados de escolaridade associaramse a menor adesão à norma de dever. Congruentemente com o resultado agora encontrado, em todos os países os homens revelaram maior adesão à norma do dever do que as mulheres. A maior adesão das mulheres à norma do direito é similar ao observado na Bélgica, Holanda e Estados Unidos. 


\section{CONCLUSŌES}

De uma forma sintética, pode-se afirmar que o trabalho é uma importante esfera da vida, sendo elemento ponderável na definição da identidade dos indivíduos (algo inferido do nivel de centralidade encontrado neste estudo); os motivos associados ao fato de trabalhar revelam a predominância da função expressiva (ter um trabalho interessante e auto-realizador) ao lado da função econômica (rendimentos e ganhos). Por outro lado, as normas societais que colocam o trabalho mais como um direito são mais fortemente introjetadas do que aquelas que enfatizam uma relação de obrigação ou dever do indivíduo para com a sociedade.

Considerando-se o conjunto de trabalhadores participantes do estudo, os dados encontrados apresentam-se, na maioria dos seus aspectos, congruentes com aqueles observados no estudo original. Embora aIgumas diferenças possam ser atribuídas a especificidades culturais locais, todos os resultados obtidos encontram paralelo em outros países que participaram do estudo original. A amostra baiana apresenta resultados que se aproximam dos da Inglaterra, no tocante à centralidade do trabalho; similares aos da Holanda, quando se trata das normas societais e dos produtos valorizados. No caso do Brasil, os resultados parecem coerentes com os encontrados por Soares ${ }^{24}$, embora a autora tenha trabalhado com uma nova estrutura conceitual, construída a partir da análise fatorial dos dados obtidos através do mesmo instrumento proposto pelo MOW.

As diferenças entre os dados dos estudos realizados revelam que contextos culturais distintos parecem ter um impacto importante no significado que o trabalho assume na vida dos indivíduos. $O$ peso atribuído aos aspectos econômicos não aparece neste estudo com a mesma força que se verificou nos diversos países da pesquisa realizada pelo MOW. Constatase também que a maior adesão às normas de direito pode significar uma revisão na ética tradicional do trabalho, o que se encontra de forma diferenciada por grupos de trabalhadores analisados. Características pessoais e ocupacionais relacionam-se

com núveis distintos de adesāo à ética tradicional, que encara o trabalho como um dever ou um sacrifício.

As diferenças observadas entre os diversos segmentos da amostra estudada (algo também observado no estudo do MOW, dentro de cada país) fortalece a conclusão do citado estudo de que "o significado do trabalho é uma estrutura complexa e altamente diferenciada no nivel do individuo"25. Os

\section{Quando os resultados da Bahia são comparados aos de outros países, indicam que o padrão encontrado na Bahia aproxima- se daquele observado nas sociedades ocidentais, diferenciando-se do Japão, onde o peso do trabalho é mais elevado, superando inclusive a esfera família.}

resultados relativos à natureza da ocupação, gênero e nível de escolaridade, fortemente próximos daqueles encontrados nos diversos países, apontam para impactos importantes no nível do significado do trabalho no futuro, considerando-se as transformaçôes em curso na composiçäo da força de trabalho.

Finalmente, é importante destacar que o conjunto de dados apresentado deve ser entendido como um ponto de partida para estudos que ampliem a compreensão dos fatores associados às diferenças detectadas entre os vários segmentos da amostra. Eles podem ser considerados, também, um passo inicial para compreender as transformaçōes em curso nos contextos de trabalho e seus impactos no plano do significado que esta importante esfera vital possui para o trabalhador brasileiro. Ampliar o contingente de indivíduos assim como incorporar uma dimensāo longitudinal sāo os principais desafios para pesquisas posteriores. $\square$

0950603
24. SOARES, C. R. Op. cit.

25. MOW. Op. cit., p. 251. 